\title{
O ambiente está adequado? Prosseguindo com a discussão
}

Juliane Figueiredo Fonseca UFRJ

Paulo Afonso Rheingantz UFRJ

\section{RESUMO}

Este artigo apresenta a Análise Ergonômica Experiencial do Ambiente Construído (AEE), em continuidade à discussão da Avaliação Ergonômica do Ambiente Construído proposta por Villarouco. Visa contribuir para o processo de concepção de ambientes construídos, a partir da interface entre duas metodologias de análise: Intervenção Ergonomizadora e Abordagem Experiencial da Avaliação Pós-Ocupação. Seu foco nos aspectos físicos, funcionais, cognitivos e culturais das demandas dos usuários do ambiente construído possibilita uma compreensão mais apurada das relações humano-ambiente e contribui para a concepção de ambientes mais responsivos e humanizados.

\section{The environment is suited? Pursuing the discussion}

\section{ABSTRACT}

This article introduces the theme of Built Environment Ergonomics Experiential Evaluation (EEE), and discusses the proposals on the subject by Villarouco. It aims to contribute to the design process of built environments from the interface between two methods of analysis: Ergonomics Intervention and Experiential Post-Occupancy Evaluation. Its focus on the physical, functional, cognitive and cultural demands of the users of built environment enables a more accurate understanding of the relationships between human beings and the environment and contributes to the design of more responsive and humanized environments.

\section{KEYWORDS}

Ergonomics experiencial evaluation, suitability of the built environment. 


\section{INTRODUÇÃO}

Com o propósito de dar continuidade à discussão iniciada por Villarouco $(2002,2007 b)$ relativa ao desenvolvimento de uma abordagem de Avaliação Ergonômica do Ambiente Construído, neste artigo procuramos relacionar as metodologias da Intervenção Ergonomizadora (IE) e da Abordagem Experiencial da Avaliação Pós-Ocupação (APO Experiencial) com o processo de concepção do ambiente construído.

Para contemplar isso, ele foi estruturado segundo três diferentes procedimentos: inicialmente, foi adotada a sistematização da IE como passos metodológicos para a proposta de Análise Ergonômica Experiencial do Ambiente Construído (AEE); a seguir, em função dos fatores envolvidos em uma APO, foram definidos três grupos de análise - Análise da Tarefa, relacionada com os fatores comportamentais, Análise da Percepção Físico-Espacial, com os fatores técnicos e funcionais, e Análise da Percepção Ambiental, com os fatores cognitivos-experienciais -, avaliados com base em um conjunto de atributos de desempenho previamente definidos; finalmente, a partir dos métodos da IE e da APO Experiencial, foram configurados os procedimentos da AEE.

A IE ${ }^{1}$ é uma vertente metodológica da Ergonomia desenvolvida por Moraes e Mont'Alvão (2005), que se dedica ao estudo pormenorizado da tarefa e das atividades que a constituem. A APO, por sua vez, é uma vertente metodológica interdisciplinar utilizada para avaliar o desempenho do ambiente construído em uso, segundo a ótica de seus usuários (PREISER et al., 1988; ORNSTEIN, 1992; BECHTEL, 1997; STOKOLS, 1996; RHEINGANTZ, 2000, entre outros).

A Abordagem Experiencial da APO (APO Experiencial), em desenvolvimento pelos pesquisadores do grupo Qualidade do Lugar e Paisagem (ProLUGAR), vinculado ao Programa de Pós-graduação em Arquitetura da FAU/ UFRJ, implica na transformação da postura do observador, que deve incorporar as sensações e as emoções experienciadas durante a observação do ambiente construído (RHEINGANTZ, 2004). A IE e a APO Experiencial procuram relacionar as atividades reais e o desempenho dos ambientes em uso com as necessidades físicas, funcionais, culturais e cognitivas de seus usuários.

A necessidade de sistematizar uma abordagem de avaliação do ambiente construído tem sido apontada por diversos autores da Ergonomia (REIS, 2001; BINS ELY, 2003; VILLAROUCO, 2001b, 2002; ROSCIANO; ALMEIDA, 2002, 2004; CASTRO; FONSECA, 2004, 2006) e da APO (PREISER et al., 1988; PREISER, 1999; BECHTEL, 1997; ORNSTEIN, 1992, 1995, 1996; RHEINGANTZ, 1995, 2000, 2004). Todos eles reconhecem que os procedimentos de concepção projetual não são suficientes para a análise do desenvolvimento das situações de uso, especialmente as relacionadas com os ambientes concebidos para o trabalho (investigação das tarefas e das atividades realizadas), nem para uma compreensão apurada das necessidades físicas, funcionais, cognitivas e culturais das pessoas.

Assim, como os projetistas podem conceber ambientes construídos mais responsivos às necessidades das pessoas que os vivenciam e adequados à realização das tarefas e atividades a que se destinam? Como podem identificar e compreender essas demandas? Essas indagações surgem do reconhecimento da diversidade de fatores e/ou aspectos relacionados com a adequabilidade do ambiente construído. Esse reconhecimento justifica a análise ergonômica do ambiente construído, visando identificar e sistematizar esses fatores e/ou aspectos, bem como a forma mais adequada de apreendê-los.

A contribuição de Villarouco (2001a, 2001b, 2002, 2004, 2005, 2007a, 2007b) tem sido importante para aprimorar os procedimentos e a estrutura da análise ergonômica do ambiente construído. Em Avaliação ergonômica do projeto arquitetônico (VILLAROUCO, 2002), a autora apresenta um leque de preocupações contempladas na concepção de ambientes ergonomicamente adequados, envolvendo elementos da Antropometria, da Psicologia Ambiental, da Ergonomia Cognitiva e da Análise Ergonômica do Trabalho (AET), além de aspectos relacionados com o conforto térmico, acústico, lumínico, cromático e acessibilidade integral. Movida pelo desejo de discutir as bases de uma sistematização para a análise do ambiente, em $O$ ambiente está adequado?, Villarouco (2007) delineia uma metodologia de Avaliação Ergonômica do Ambiente Construído.

Neste trabalho propomos incorporar os elementos da sistematização de procedimentos da IE e da APO Experiencial à Análise Ergonômica do Ambiente Construído originalmente proposta por Villarouco.

A seguir, e em seqüência, são apresentados:

a) uma breve descrição de cada uma das abordagens e metodologias adotadas;

b) a proposta preliminar de uma Análise Ergonômica Experiencial do Ambiente Construído (AEE); e

c) a sistematização de um conjunto de procedimentos necessários para sua utilização, com base na IE e na APO Experiencial. Nas considerações finais, são discutidas as possíveis contribuições da AEE para o processo projetual de ambientes mais responsivos e humanizados.

\section{INTERVENÇÃO ERGONOMIZADORA (IE)}

Uma atuação mais responsiva no processo de concepção projetual demanda maior atenção e conhecimento dos 
projetistas sobre a importância, as implicações e os reflexos das relações humano-ambiente. No entanto, poucos são os profissionais de projeto que reconhecem e consideram as reais demandas e relações dos usuários dos ambientes que concebem. Essa prática decorre da própria natureza da teoria da arquitetura, que tem focalizado mais.

$\mathrm{O}$ relacionamento do arquiteto com o artefato que ele produz e as ideologias e testemunhos individuais dos projetistas do que o relacionamento entre as pessoas (individualmente ou em geral) e o ambiente construído (ZEISEL, 1981, p. 8).

Mas esse problema não se restringe aos projetistas, uma vez que de modo geral são contratados para conceber projetos com base em informações negociadas com os proprietários ou administradores das organizações demandantes, que também tendem a não atentar para as reais necessidades das diferentes atividades implicadas, e muito menos ainda para as demandas individuais das pesso-

as que vão desempenhar essas atividades. Como resultado, a maioria das pessoas trabalha em ambientes anônimos e impessoais, sendo forçada a investir na adaptação do ambiente às suas características pessoais; esses ambientes dificultam e interferem em suas necessidades comportamentais de trabalho, reduzindo sua produtividade organizacional (SMITH; KEARNY, 1994).

Segundo Smith e Kearny (1994), é necessário prestar maior atenção ao que acontece quando as pessoas estão pensando e como o ambiente interfere de maneira positiva ou negativa, especialmente nas atividades que exigem concentração ou trabalho mental. É preciso estudar com mais cuidado como os diferentes tipos de ambientes estimulam o pensamento e sua posterior transformação em ações. Como as pessoas têm uma capacidade limitada e variável para prestar atenção a estímulos externos, uma configuração das zonas de conforto (seus limites de capacidade de atenção) que permita eliminar ou reduzir as interferências no trabalho mental possibilita que seu desempenho seja melhorado.

Esse desconhecimento gera lacunas nas premissas projetuais, com reflexos negativos no processo de ocupação e uso dos ambientes. Metodologias como a Intervenção Ergonomizadora (IE) e a Abordagem Experiencial da Avaliação Pós-Ocupação (APO Experiencial), que consideram a vivência e a experiência do lugar por seus usuários, podem auxiliar na compreensão e na apreensão das relações humano-ambiente, reduzindo a necessidade de os usuários investirem na adaptação do ambiente às suas características pessoais. Elas também podem contribuir para: (a) superar a crença na adaptabilidade humana, que produz lugares genéricos, autoajustáveis a pessoas de qualquer tamanho (foco na oferta); (b) reconhecer a necessidade de produzir um ambiente mais responsivo, adaptável às necessidades de cada indivíduo; (c) reconhecer que as pessoas são treinadas desde pequenas a se adaptar, a ajustar-se aos ambientes (SMITH; KEARNY, 1994); e (d) relacionar as futuras demandas com a concepção e produção de ambientes construídos como elementos de interação com o meio social.

A IE, desenvolvida por Moraes e Mont'Alvão (2005), é uma vertente metodológica da Ergonomia que se dedica ao estudo pormenorizado da tarefa e das atividades que a constituem, envolvendo: o objetivo a atingir, os requisitos 
no sistema), dados administrativos (função, número de funcionários, turnos de trabalho, etc.) e características das atividades.

\subsection{Diagnose ergonômica}

Visa aprofundar a análise dos problemas ergonômicos identificados e compreende: Análise Comportamental da Tarefa, Análise da Ambiência da Tarefa, Perfil e Voz dos usuários, em que são analisados os fatores cognitivos e experienciais relativos à percepção e vivência das relações humano $\times$ tarefa $\times$ ambiente, os fatores comportamentais relativos à tarefa realizada e os fatores técnicos e funcionais relativos ao ambiente em uso.

\subsection{Projetação ergonômica}

Etapa de concepção do ambiente construído, onde o conhecimento e a compreensão da vivência e uso do ambiente pelos usuários no desempenho de suas tarefas e a apreensão de suas necessidades e expectativas devem possibilitar a concepção de projetos mais adequados e responsivos a tais condicionantes.

\subsection{Avaliação e validação ergonômica}

Apresentação dos argumentos, propostas e alternativas projetuais aos usuários.

\section{ABORDAGEM EXPERIENCIAL DA AVALIAÇÃO PÓS-OCUPAÇÃO}

A APO é um processo sistematizado e rigoroso de avaliação de edifícios, passado algum tempo de sua construção e ocupação, que focaliza os ocupantes do edifício e suas necessidades. A partir das demandas dos usuários são avaliadas as consequências das decisões projetuais no desempenho da edificação e, em função dos objetivos do cliente e do tempo necessário, a APO possibilita a adoção de melhorias a curto, médio e longo prazo (PREISER et al., 1988).

Suas origens remontam a três vertentes distintas de pesquisa iniciadas nos Estados Unidos e Canadá, as duas primeiras no final dos anos 40, e a terceira no final dos anos 50: a Psicologia ambiental, que estuda as relações entre ambiente e comportamento, o desempenho dos edifícios (U.S. National Institute of Standards and Technology e Committee E06 on Performance of Buildings of ASTM) e a consolidação da Architectural Programming ${ }^{3}$ ou Programação Arquitetônica.

Tradicionalmente as pesquisas em APO têm como meta a avaliação de três conjuntos de fatores: a) Técnicos - aspectos construtivos, condições de conforto ambiental, segurança e consumo energético;

b) Funcionais - estudo do dimensionamento dos ambientes, dos fluxos presentes, das possibilidades de realizar as atividades previstas, do desempenho organizacional e da acessibilidade; e

c) Comportamentais - elementos como atividades que acontecem no local, relações entre uso real e uso previsto, satisfação/aspirações dos usuários da edificação (PREISER et al., 1988; ORNSTEIN, 1992). Rheingantz, Del Rio e Duarte (2002) propõem uma quarta categoria de fatores:

d) Culturais - que possibilitam reconhecer as transformações significantes produzidas nas relações entre os grupos humanos e o ambiente construído, seus aspectos cognitivos (subjetivos), seus valores declarados e reais que influenciam e são influenciados pelo uso e pela operação dos edifícios.

A exemplo da contribuição de Villarouco (2002) para a Ergonomia - que reconhece a influência direta das sensações experimentadas ao conviver em um determinado ambiente nas ações de seus usuários - a partir de 2003, o grupo de pesquisa Qualidade do Lugar e Paisagem (ProLUGAR) ${ }^{4}$ vem desenvolvendo e testando a Abordagem Experiencial da APO (APO Experiencial), que possibilita incorporar aos procedimentos clássicos da APO as sensações, sentidos e emoções do observador vivenciadas durante a observação.

A APO Experiencial implica transformação da postura ou atitude do observador. Em lugar da neutralidade e distanciamento preconizados pela abordagem comportamental, o observador deve atentar e registrar os estímulos, sensações e emoções produzidos durante sua experiência de observação. Valendo-se da empatia (THOMPSON, 1999), o observador também deve procurar colocar-se no lugar dos usuários na tentativa de:

a) compreender e incorporar a sua experiência vivenciada no ambiente;

b) identificar seus valores, expectativas e necessidades; e

c) propor medidas e recomendações corretivas nas etapas de programação e de projeto (ALCANTARA; BARBOZA; RHEINGANTZ, 2006).

Para dar conta disso, além dos instrumentos tradicionalmente utilizados em uma APO - walkthrough, questionário, entrevista, checklist de fatores técnicos, funcionais e comportamentais, seleção visual, mapeamento visual, preferências visuais etc. -, a APO Experiencial se vale de outros procedimentos que possibilitam identificar a percepção ambiental dos usuários, especialmente a observação incorporada, a matriz de descobertas (RODRIGUES, 2005) e o poema dos desejos (SANOFF, 1991). 


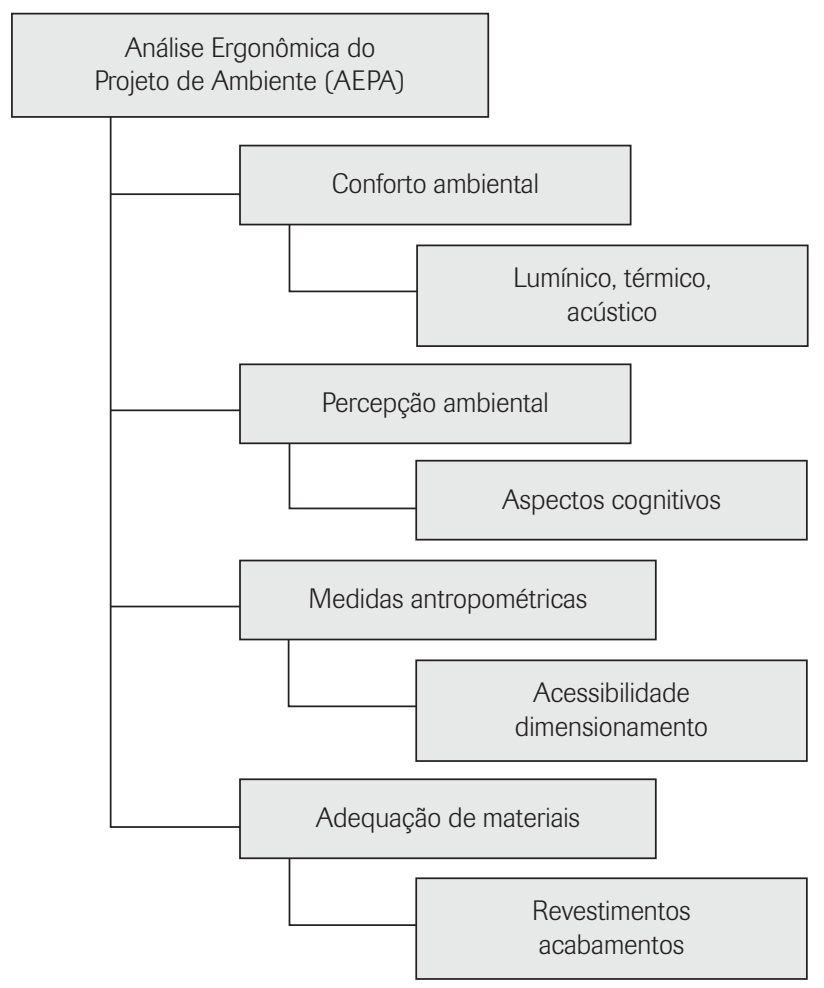

Figura 1: Fatores componentes de uma Análise Ergonômica do Projeto de Ambiente (AEPA). Fonte: Villarouco et al. (2005)

Enquanto a IE fundamenta-se na análise da tarefa e das atividades humanas realizadas no ambiente construído, a APO Experiencial fundamenta-se na análise de desempenho dos ambientes em uso como suporte para as atividades humanas, segundo a percepção do observador e dos usuários do ambiente. Na aplicação dos procedimentos de ambas as metodologias, o projetista deve portar-se como um observador atento e aberto ao que acontece no ambiente em uso.

\section{ANÁLISE ERGONÔMICA EXPERIENCIAL DO AMBIENTE CONSTRUÍDO}

Nesta seção apresentaremos a proposta de sistematização para a Análise Ergonômica Experiencial do Ambiente Construído (AEE), a partir das bases lançadas por Villarouco $(2002,2007 b)$.

Segundo Villarouco (2002), elaborar um projeto a partir de um enfoque ergonômico é antever sua utilização, é conjugar condicionantes físicos, cognitivos, psicossociais e culturais, objetivando identificar o elenco de variáveis envolvidas na adequabilidade do ambiente construído. Uma completa avaliação ergonômica do ambiente abrange um vasto leque de variáveis composto pelos elementos da Antropometria, da Percepção Ambiental, da Ergonomia Cognitiva e da Análise Ergonômica do Trabalho (AET), assim como conceitos de conforto térmico, acústico e lumínico e acessibilidade integral (Figura 1).

Villarouco (2007b) considera que uma abordagem pensada para verificar a adequação ergonômica do ambiente construído deve contemplar duas fases - uma de ordem física do ambiente e outra de identificação da percepção do usuário em relação a esse ambiente. As análises e recomendações são geradas da confrontação dos dados obtidos nessas duas fases.

Os contornos do método proposto por Villarouco têm como base a Análise Ergonômica do Trabalho (AET), que teve cada uma de suas etapas adaptadas para a análise dos aspectos físicos do ambiente construído em uso. Para a identificação de variáveis da percepção dos usuários foi adotado um procedimento do campo da Percepção Ambiental - a Constelação de Atributos. A partir do cruzamento dos dados obtidos nos dois métodos, são feitas análises no intuito de verificar as relações entre as variáveis do ambiente de trabalho e a produtividade.

Iniciamos nossas reflexões apresentando os contornos da abordagem a ser proposta. Ao contrário de Villarouco (2007b), adotamos a sistematização de procedimentos da Intervenção Ergonomizadora (IE). A escolha da IE se deve ao conhecimento e familiaridade por parte dos autores. As etapas e os procedimentos da IE foram adaptados à análise dos fatores envolvidos em uma avaliação do ambiente construído, complementados pelos procedimentos da APO Experiencial.

A partir da apresentação dos fatores que compõem uma Análise Ergonômica do Ambiente Construído, no quadro elaborado por Villarouco (2005), procuramos reorganizá-los em grupos e incorporar alguns outros segundo a análise dos fatores de uma APO Experiencial - comportamentais, técnicos, funcionais e cognitivos-experienciais. Para avaliar esses fatores, selecionamos alguns atributos de análise de desempenho inspirados na CPBR (Centre for Building Performance Research) checklist (BAIRD et al., 1995), no conjunto de atributos de desempenho, desenvolvidos por Rheingantz (2000), por Abrantes (2004) ${ }^{5}$ e Moraes (2005). Cabe esclarecer que, neste artigo, foram selecionados somente os atributos considerados básicos para uma análise do ambiente construído, sendo possível a inserção de outros, em função da especificidade do ambiente e das tarefas a serem analisadas.

O processo de análise foi estruturado em três grupos:

i) Análise da Tarefa - relacionada com os fatores comportamentais e avaliados a partir dos atributos da 
Análise Ergonômica Experencial

do Ambiente Construído (AEE)

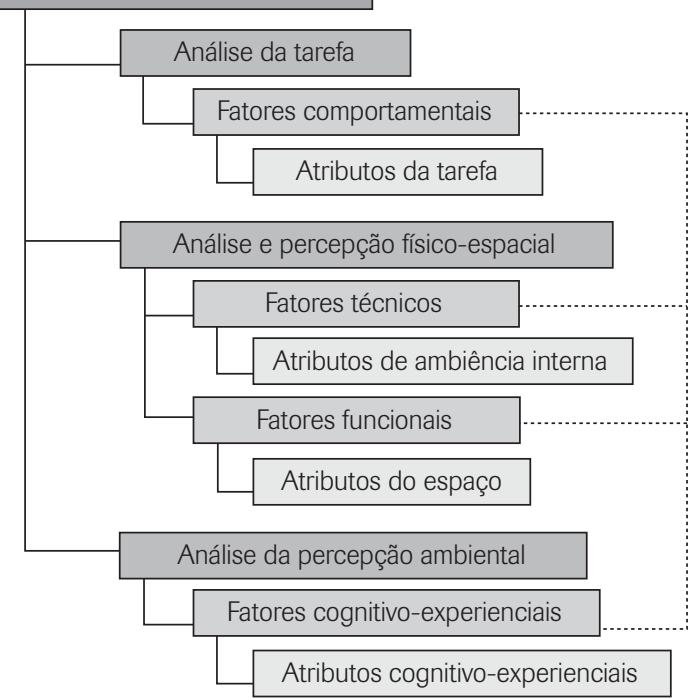

Figura 2: Fatores componentes de uma Análise Ergonômica Experiencial do AC.

tarefa (tarefa, duração, constância, familiaridade, ritmo e sequência);

ii) Análise da Percepção Físico-espacial - relacionada com os fatores técnicos, avaliados a partir dos atributos de ambiência interna (conforto do ambiente interno e adequação dos materiais) e fatores funcionais, avaliados a partir dos atributos de espaço (área útil, flexibilidade de layout, circulação interna, antropometria, acessibilidade); e

iii) Análise da Percepção Ambiental - relacionada com os fatores cognitivos-experienciais, avaliados a partir dos atributos cognitivos-experienciais -imaginabilidade e adaptabilidade (Figura 2).

Propomos que a Análise Ergonômica Experiencial do Ambiente Construído (AEE) seja realizada sob o ponto de deverá ser dada maior ênfase às relações e sensações humano $\times$ ambiente do que às medições dos fatores técnicos $\mathrm{e}$ funcionais e às normas de trabalho prescritas, relacionadas com os aspectos comportamentais. Isso significa que todos os atributos deverão ser avaliados através da percepção do pesquisador (observador) e dos usuários.

\subsection{Sistematização da Abordagem Ergonômica Experiencial do Ambiente Construído (AEE)}

Conforme mencionado, foram adotadas as fases da análise tradicional da IE e adaptadas para a análise de desempenho do AC com o foco nas demandas do usuário, na tarefa e nas atividades realizadas.

\section{Etapa 1: Apreciação Ergonômica do Ambiente Construído}

Etapa exploratória e de delimitação dos problemas ergonômicos. O quadro de Categorização dos Problemas Ergonômicos foi adaptado em função dos atributos de desempenho do AC adotados (Tabela 1):

Nesta fase devem ser aplicados os seguintes procedimentos:

- Observações exploratória/assistemáticas e incorporadas no local de trabalho;

- Análise walkthrough;

- Entrevistas não estruturadas com supervisores e trabalhadores;

- Registros fotográficos e/ou em vídeo;

- Levantamento físico dos ambientes.

\section{Etapa 2: Diagnose Ergonômica do Ambiente Construído}

Etapa de aprofundamento da análise dos problemas ergonômicos identificados, compreendendo: Análise Comportamental da Tarefa, Análise da Ambiência da Tarefa e Perfil e Voz dos usuários.

(a) Análise Comportamental da Tarefa - implica na análise dos fatores comportamentais. Compreende o estudo pormenorizado das atividades realizadas em situações reais de trabalho, sendo analisados os seguintes atributos da tarefa: tarefa, duração, constância, familiaridade, ritmo e sequência.

(b) Análise da Ambiência Física e Perceptiva da Tarefa - implica na análise dos fatores técnicos e funcionais do ambiente em uso. Quanto aos fatores técnicos avaliam-se os atributos de ambiência interna, sendo eles: conforto interno - em que os resultados do levantamento dos dados físicos do ambiente vista da Abordagem Experiencial da APO, ou seja, que o pesquisador, durante a observação do ambiente em uso, incorpore suas sensações e emoções, assim como busque absorver a experiência e vivência do usuário. Dessa forma, 
Tabela 1: Categorização dos problemas ergonômicos e dos atributos de desempenho do AC

\begin{tabular}{|c|c|c|}
\hline \multicolumn{3}{|c|}{ FATORES COMPORTAMENTAIS } \\
\hline Atributos da Tarefa & Descrição & Autor de referência \\
\hline Tarefa & Compreensão do trabalho prescrito $\times$ trabalho real, da tarefa e atividades & Moraes e Mont’Alvão (2005) \\
\hline Duração & $\begin{array}{l}\text { O tempo de permanência em um ambiente de trabalho age diretamente sobre o } \\
\text { comportamento ambiental de um indivíduo }\end{array}$ & $\begin{array}{l}\text { Sommer (1979); } \\
\text { Fischer (1994) }\end{array}$ \\
\hline Constância & $\begin{array}{l}\text { Fator que proporciona experiências ambientais diferentes conforme a periodicidade e } \\
\text { permanência no ambiente }\end{array}$ & $\begin{array}{l}\text { Sommer (1979); } \\
\text { Fischer (1994) }\end{array}$ \\
\hline Familiaridade & Como se familiariza com o ambiente onde passa a maior parte do seu tempo produtivo & $\begin{array}{l}\text { Sommer (1979); } \\
\text { Tuan (1980) }\end{array}$ \\
\hline Ritmo & A rapidez com que as pessoas se movem e a dinâmica com que os eventos se passam & Sommer (1979) \\
\hline Sequência & Diz respeito aos caminhos percorridos e experienciados no ambiente de trabalho & Sommer (1979) \\
\hline \multicolumn{3}{|c|}{ FATORES TÉCNICOS } \\
\hline $\begin{array}{l}\text { Atributos de ambiência } \\
\text { interna }\end{array}$ & Descrição & Autor de referência \\
\hline Conforto interno & $\begin{array}{l}\text { Relativos à qualidade do ambiente interno necessário para o bem-estar físico e também } \\
\text { emocional dos usuários; são: conforto visual, sonoro, tátil, térmico e aeróbico }\end{array}$ & $\begin{array}{l}\text { CPBR checklist, } \\
\text { Rheingantz (2000) }\end{array}$ \\
\hline $\begin{array}{l}\text { Adequação dos } \\
\text { materiais }\end{array}$ & $\begin{array}{l}\text { Aparência, adequação, conservação, limpeza e manutenção dos materiais de acabamento } \\
\text { dos revestimentos propostos para o ambiente (piso, teto e parede) e mobiliário }\end{array}$ & Moraes e Mont'Alvão (2005) \\
\hline \multicolumn{3}{|c|}{ FATORES FUNCIONAIS } \\
\hline Atributos do espaço & Descrição & Autor de referência \\
\hline Área útil & Área disponível para a realização das tarefas e atividades & $\begin{array}{l}\text { CPBR checklist; } \\
\text { Rheingantz (2000) }\end{array}$ \\
\hline Flexibilidade do layout & Capacidade de mudança do espaço físico & $\begin{array}{l}\text { CPBR checklist; } \\
\text { Rheingantz (2000) }\end{array}$ \\
\hline Espaços de apoio & $\begin{array}{l}\text { Espaço para recepção, copa e descanso, área para fumantes, instalações para } \\
\text { funcionários, para prestadores de serviços, sanitárias etc. }\end{array}$ & $\begin{array}{l}\text { CPBR checklist; } \\
\text { Rheingantz (2000) }\end{array}$ \\
\hline Circulação interna & $\begin{array}{l}\text { Posição, sinalização/comunicação visual, distâncias a serem percorridas para a realização } \\
\text { das atividades da tarefa e atividades }\end{array}$ & $\begin{array}{l}\text { CPBR checklist; Rheingantz } \\
\text { (2000) }\end{array}$ \\
\hline Antropométricos & $\begin{array}{l}\text { Relacionados à adequação do dimensionamento do espaço e mobiliário aos percentis } \\
\text { extremos }\end{array}$ & Moraes e Mont’Alvão (2005) \\
\hline Acessibilidade & $\begin{array}{l}\text { Facilidade de acesso para todas as pessoas, normais ou com necessidades especiais } \\
\text { (portadores de deficiências, acidentados, gestantes, idosos e crianças) }\end{array}$ & $\begin{array}{l}\text { Rheingantz (2000); } \\
\text { Moraes e Mont'Alvão (2005) }\end{array}$ \\
\hline \multicolumn{3}{|c|}{ FATORES COGNITIVOS-EXPERIENCIAIS } \\
\hline $\begin{array}{l}\text { Atributos cognitivos- } \\
\text { experienciais } 1\end{array}$ & Descrição & Autor de referência \\
\hline Imaginabilidade & As imagens que os usuários fazem do seu ambiente de trabalho & Lynch (1960) \\
\hline Adaptabilidade & $\begin{array}{l}\text { Como se estabelece o sentimento de posse por meio da personalização e adequação do } \\
\text { lugar de trabalho }\end{array}$ & $\begin{array}{l}\text { Lynch (1960); Sommer } \\
\text { (1979); Fischer (1994) }\end{array}$ \\
\hline
\end{tabular}

com instrumentos e técnicas específicas devem ser confrontados com o levantamento da percepção do usuário - e adequação dos materiais de piso, parede, teto e mobiliário.

Quanto aos fatores funcionais, avaliam-se os atributos do espaço necessário para a realização das tarefas e atividades requeridas em um ambiente de trabalho. Tais como área útil, flexibilidade do layout, espaços de apoio, circulação interna, antropométricos, acessibilidade.

(c) Perfil e Voz dos usuários - implica na análise dos fatores cognitivos-experienciais, relacionados com a percepção do ambiente. Com a participação dos usuários avaliam-se os atributos cognitivos-experienciais de imaginabilidade e adaptabilidade.

Nesta etapa devem ser utilizados os seguintes procedimentos:

- Observações sistemática e incorporada;

- Análise walkthrough;

- Questionários e entrevistas;

- Verbalizações; 
- Registros de comportamento;

- Carta de-para;

- Mapofluxogramas;

- Mapeamento visual;

- Seleção Visual ou Preferências Visuais;

- Poema dos desejos (Wish Poem).

\section{Etapa 3: Projetação Ergonômica do Ambiente Construído}

Nesta etapa os projetistas devem lançar mão dos dados coletados na AEE realizada no ambiente em uso para a concepção de ambientes mais responsivos e humanizados.

\section{Etapa 4: Avaliação Ergonômica do Ambiente Construído}

Nesta etapa os argumentos, as propostas e alternativas projetuais devem ser apresentados e negociados com os usuários.

\subsection{Relação entre os atributos de desempenho e os métodos da IE e da APO Experiencial}

Neste item são apresentados os procedimentos da AEE, ou seja, métodos e respectivos instrumentos, que devem ser aplicados para a análise dos atributos apresentados. A análise situada ou ida ao campo é um momento privilegiado de apreensão das informações relevantes sobre as demandas físicas, técnicas, funcionais e cognitivas-experienciais dos usuários, de identificação das exigências das atividades desenvolvidas e de contato com os usuários. A Tabela 2 relaciona os métodos da IE e da APO Experiencial que podem ser adotados para a análise dos atributos de desempenho apresentados.

A Tabela 3, referente aos procedimentos da AEE, apresenta um resumo dos métodos citados, quais os instrumentos aplicados e por qual metodologia eles são empregados.

Os procedimentos e instrumentos da APO, apresentados no quadro anterior, vêm sendo aplicados desde 2004 pelo Grupo ProLUGAR (RHEINGANTZ et al., 2008) em suas avaliações de desempenho do ambiente construído, e sua incorporação aos instrumentos e procedimentos de avaliação ergonômica representa a principal contribuição deste trabalho ao desenvolvimento de uma abordagem de AEE.

A seguir é apresentada a descrição dos métodos da APO Experiencial indicados na Tabela 3.

\subsubsection{Observação incorporada}

O roteiro de campo da observação incorporada focaliza a experiência do observador no lugar. Munido dos instrumentos usuais para esse fim - prancheta, papel de rascunho, lápis macio, caderno de campo, máquina fotográfica e gravador -, o observador deve dirigir-se ao local da observação e seguir as seguintes etapas e procedimentos: (a) preparação - antes de iniciar a observação, ele deve fazer um breve relaxamento das tensões e ansiedades produzidas em seu deslocamento; (b) observação atenta - a atenção deve se voltar para os acontecimentos que se desenrolam e, na medida do possível, deixar-se envolver pela atmosfera do ambiente, iniciando um percurso à deriva. Em lugar de direcionar seus pensamentos e sentidos, deve atentar para as reações e efeitos produzidos em seu corpo e sua mente. Esse percurso deve ser complementado por fotografias contendo instantâneos ou elementos considerados relevantes pelo observador e, sempre que possível, por um gravador para registro oral de sua experiência; (c) análise in loco - terminado o percurso, ainda "contagiado" pelas emoções vivenciadas, o observador deve relatar em um gravador ou caderno de anotações suas observações; (d) análise compartilhada - a seguir deve

Tabela 2: Categorias de atributos de desempenho e métodos da IE e APO Experiencial.

\begin{tabular}{|c|c|}
\hline \multicolumn{2}{|r|}{ FATORES COMPORTAMENTAIS } \\
\hline $\begin{array}{l}\text { Atributos da tarefa: Trabalho prescrito } \times \text { trabalho } \\
\text { real, tarefa e atividades; duração, constância, } \\
\text { familiaridade, ritmo, sequência }\end{array}$ & $\begin{array}{c}\text { Walkthrough, observações assistemática, sistemática e incorporada em situação real de } \\
\text { trabalho, entrevistas, questionários, verbalizações, registros de comportamento, } \\
\text { carta de-para, mapofluxogramas }\end{array}$ \\
\hline \multicolumn{2}{|r|}{ FATORES TÉCNICOS } \\
\hline $\begin{array}{l}\text { Atributos de ambiência interna: Conforto do } \\
\text { ambiente interno; adequação dos materiais }\end{array}$ & $\begin{array}{l}\text { Walkthrough, observações assistemática, sistemática e incorporada em situação real de } \\
\text { trabalho, questionários, poema dos desejos, mapeamento visual, entrevistas }\end{array}$ \\
\hline \multicolumn{2}{|r|}{ FATORES FUNCIONAIS } \\
\hline $\begin{array}{l}\text { Atributos do espaço: Área útil; flexibilidade do } \\
\text { layout; espaços de apoio; circulação interna; } \\
\text { antropométricos }\end{array}$ & $\begin{array}{c}\text { Walkthrough, observações assistemática, sistemática e incorporada em situação } \\
\text { real de trabalho, questionário, poema dos desejos, mapeamento visual, entrevistas, } \\
\text { mapofluxograma, carta de-para }\end{array}$ \\
\hline \multicolumn{2}{|r|}{ FATORES COGNITIVOS-EXPERIENCIAIS } \\
\hline $\begin{array}{l}\text { Atributos cognitivos- experienciais: } \\
\text { Imaginabilidade; adaptabilidade }\end{array}$ & $\begin{array}{l}\text { Walkthrough, observações assistemática, sistemática e incorporada em situação real de } \\
\text { trabalho, questionário, seleção visual, poema dos desejos, mapeamento visual, entrevistas }\end{array}$ \\
\hline
\end{tabular}


ser feita uma troca de experiências e impressões vivenciadas por aqueles que compartilharam a observação, anotando-se os pontos comuns e as discrepâncias; (e) análise crítica - já no laboratório/escritório, o observador reúne os dados em novo documento, agora mais sistematicamente e devidamente fundamentado; (f) se necessário, novas observações mais estruturadas, com roteiros previamente definidos, podem ser realizadas no local.

\subsubsection{Análise walktrough}

Por ser relativamente fácil e rápida de aplicar, é um dos procedimentos mais utilizados em APOs e, em geral, precede todos os estudos e levantamentos, sendo bastante útil para identificar as principais qualidades e defeitos do edifício e de seu uso. Sua realização permite identificar, descrever e hierarquizar quais aspectos do edifício ou de seu uso merecem estudos mais aprofundados e quais técnicas e instrumentos devem ser utilizados; as falhas, os problemas e os aspectos positivos do ambiente analisado. Consiste em formar uma equipe composta por especialistas e por representantes dos usuários ou do staff da(s) organização(ões) instalada(s) no edifício ou de usuários de um determinado lugar urbano que, munida de plantas e fichas de registro, faz uma entrevista-percurso de reconhecimento ou ambientação, abrangendo todos seus ambientes considerados no estudo, bem como o modo como eles são utilizados. Para tanto, se vale de diversas técnicas de registro: mapas, plantas, checklists, gravações de áudio e de vídeo, fotografias, desenhos, diários, fichas etc. Sempre que possível a walkthrough deve ser precedida e complementada com informações extraídas das plantas dos pavimentos e de outros documentos significantes e/ou informativos.

\subsubsection{Seleção Visual (ou Preferências Visuais)}

Esse instrumento possibilita a identificação das ideias, valores, atitudes e cultura dos usuários. (SANOFF, 1977, 1990, 1991). É de grande utilidade para a compreensão do impacto causado pelos ambientes na qualidade de vida e no bem-estar dos usuários. Consiste, basicamente, na apresentação de um conjunto de imagens de ambientes (por exemplo: escritórios, salas de espera, postos de trabalho) para avaliação dos usuários e indicação da imagem que mostra o ambiente preferido pelo respondente, ou a indicação de que elementos de cada imagem são considerados bons ou ruins por meio de um conjunto de adjetivos de conotação positiva e/ou negativa de cada imagem. Essa técnica é utilizada por Sanoff como instrumento de participação dos usuários no processo projetual. Ao se depararem com uma série de possibilidades visuais e de arranjos espaciais, os respondentes são levados a comparar as alternativas, avaliar as possibilidades de cada uma e conhecer suas preferências.

\subsubsection{Mapeamento Visual}

É um instrumento que possibilita identificar a percepção dos usuários em relação a um determinado ambiente, focalizando a localização, a apropriação, a demarcação de territórios, as inadequações a situações existentes, o mobiliário excedente ou inadequado e as barreiras, entre outras características. Seus objetivos são: (a) verificar aspectos relacionados com territorialidade e apropriações; (b) avaliar a adequação do mobiliário e do equipamento existente; $\mathrm{e}$ (c) possibilitar que o usuário registre em plantas baixas humanizadas e de fácil identificação os pontos positivos e negativos do ambiente considerado. O instrumento pode ser aplicado em dois momentos distintos: no início e no final da pesquisa de campo, e pode ser associado à

Tabela 3: Quadro resumo de métodos e instrumentos da Análise Ergonômica Experiencial do AC

\begin{tabular}{|c|c|c|c|}
\hline MÉTODOS & INSTRUMENTOS & $\mathrm{IE}$ & APO \\
\hline Observações assistemática, sistemática & Caderno de campo, fotos, plantas esquemáticas & & \\
\hline Observação incorporada & Caderno de campo, fotos, plantas esquemáticas & & \\
\hline Análise walkthrough & $\begin{array}{l}\text { Ficha de avaliação técnica - Walkthrough, fotografias, croquis gerais, gravação de } \\
\text { áudio e vídeo }\end{array}$ & & \\
\hline Questionário & Questionário (perguntas estruturadas e semiestruturadas) & & \\
\hline Entrevista & Entrevista (perguntas não estruturadas, semiestruturadas e estruturadas) & & \\
\hline Verbalizações & Caderno de campo, gravador e filmadora & & \\
\hline Registros de comportamento & Fichas de registro, fotos e/ou filmagens & & \\
\hline Carta de-para & Caderno de campo, ficha de registro, plantas esquemáticas & & \\
\hline Mapofluxogramas & Caderno de campo, ficha de registro, plantas esquemáticas & & \\
\hline Seleção visual & Ficha de seleção visual, imagens de ambientes & & \\
\hline Mapeamento visual & Planta do ambiente & & \\
\hline Poema dos desejos (Wish Poem) & “Poema” & & \\
\hline
\end{tabular}


Análise da Tarefa na identificação do território de trabalho e contatos.

\subsubsection{Poema dos desejos (Wish Poem)}

Desenvolvido por Sanoff (1991), esse instrumento encoraja os usuários a refletir e registrar em uma folha de papel a descrição do "ambiente de seus sonhos". Diferentemente das rimas dos poemas tradicionais, o poema dos desejos deve conter um conjunto de frases representativas dos de-

i) definir os passos metodológicos para a análise do ambiente em uso;

ii) identificar e sistematizar os fatores e/ou aspectos, bem como os respectivos atributos de desempenho envolvidos na adequabilidade do ambiente em uso;

iii) e definir uma forma adequada de apreendê-los.

A contribuição deste artigo para a discussão iniciada por Villarouco envolve os seguintes aspectos:

1) Sistematização dos fatores envolvidos na análise ergonômica do ambiente em uso; tal sistematização em três grupos de análise relacionados com os fatores de uma APO e avaliados a partir de um conjunto previamente determinado de atributos de desempenho - (i) Análise da Tarefa, com os fatores comportamentais avaliados a

sejos e sentimentos dos usuários com relação ao ambiente considerado. As sentenças são sempre iniciadas da mesma forma, "Eu gostaria que...", e devem evidenciar os sonhos, desejos, preferências, inadequações (aspectos de ergonomia e de projeto), bem como insatisfações e sugestões de mudanças.

\section{CONSIDERAÇÕES FINAIS}

Conforme o próprio título sugere, a discussão sobre o tema não se esgota neste artigo. Para a sistematização e consolidação de um processo de AEE, ainda existem muitas questões a ser analisadas e aprofundadas. Considerando a observação abaixo:

A realidade é uma proposição explicativa... e a ciência é um domínio cognitivo válido para todos aqueles que aceitam o critério de validação das explicações científicas. Maturana (2001, p. 37)

Suas implicações e desdobramentos ainda precisam ser mais bem analisados e validados pela comunidade acadêmica. Logo, é preciso prosseguir com a discussão!

Partimos do pressuposto de que o entendimento da complexidade dos fatores envolvidos nas relações estabelecidas entre o coletivo humano $\times$ tarefa $\times$ máquina $\times$ ambiente construído é fundamental para a concepção de ambientes mais responsivos às demandas dos usuários $\mathrm{e}$ das atividades desempenhadas por eles.

Para a compreensão e apreensão desses fatores, delineamos, a partir dos trabalhos de Villarouco (2002, 2007b), uma abordagem de AEE com base na sistematização de procedimentos da IE e da APO Experiencial, a qual teve o propósito de: partir dos atributos da tarefa (tarefa, duração, constância, familiaridade, ritmo e sequência), (ii) Análise da Percepção Físico-Espacial, com os fatores técnicos avaliados a partir dos atributos de ambiência interna (conforto do ambiente interno e adequação dos materiais) e fatores funcionais avaliados a partir dos atributos de espaço (área útil, flexibilidade de layout, circulação interna, antropometria, acessibilidade), e (iii) Análise da Percepção Ambiental, com os fatores cognitivosexperienciais avaliados a partir dos atributos cognitivos-experienciais (imaginabilidade e adaptabilidade) - permite uma apreensão clara dos aspectos envolvidos nas relações internas do coletivo humano $\times$ tarefa $\times$ máquina $\times$ ambiente construído.

2) Incorporação dos procedimentos da APO Experiencial aos instrumentos adotados na IE, baseados na percepção do observador e dos usuários, representa uma significativa contribuição para a melhor compreensão das relações estabelecidas entre o coletivo humano $\times$ tarefa $\times$ máquina $\times$ ambiente construído estudado, reduzindo a necessidade dos usuários investirem na adaptação do ambiente às suas características pessoais.

3) Relação entre os atributos de desempenho e os métodos de análise das metodologias adotadas, apresentada na Tabela 2, fornece aos projetistas a operacionalização da apreensão dos fatores envolvidos na adequabilidade do AC.

A incorporação da AEE ao processo de concepção projetual disponibiliza um conjunto de procedimentos adequados para a análise do desenvolvimento das situações de uso e para a compreensão apurada das necessidades físicas, funcionais, cognitivas e culturais das pessoas e, consequentemente, pode auxiliar os projetistas na elaboração de ambientes mais responsivos e humanizados. 


\section{Artigo recebido em 26/01/2009 Aprovado para publicação em 05/08/2009}

\section{NOTAS}

1. Neste artigo, dentre as metodologias de análise ergonômica existentes, adotamos a Intervenção Ergonomizadora de Moraes e Mont'Alvão (2005) pelo fato de esta ser a base de pesquisa e atuação da primeira autora. Sua experiência foi iniciada em 2003, ano de início de sua especialização em Ergonomia no Núcleo de Ergonomia e Segurança do Trabalho da UFJF e de seu mestrado em Design na PUC-Rio, que teve como orientadora a profa. Cláudia Mont’Alvão.

\section{REFERÊNCIAS}

ABRANTES, M. Um Olhar cognitivo sobre o lugar de trabalho: avaliação de desempenho em ambiente de escritório: estudo de caso em empresa de advocacia. Rio de Janeiro, 2004. 221 p. Dissertação (Mestrado em Arquitetura) - Universidade Federal do Rio de Janeiro.

ALCANTARA, D.; BARBOSA, A.; RHEINGANTZ, P. Percursos à Deriva na Investigação do Lugar: o caso do Corredor Cultural, Rio de Janeiro. In: NUTAU'2006. Anais... São Paulo: FAUUSP, 2006.

ALMEIDA, M. Ergonomia e Arquitetura: uma vinculação transdisciplinar. In: CONGRESSO LATINO- AMERICANO DE ERGONOMIA, 7, SEMINÁRIO BRASILEIRO DE ACESSIBILIDADE INTEGRAL, 1, CONGRESSO BRASILEIRO DE ERGONOMIA, 12, Recife, 2002. Anais...

ALMEIDA, M. Ergonomia e Teoria do Projeto Arquitetônico: investigando a lógica de utilização para projetar a de funcionamento. In: CONGRESSO BRASILEIRO DE ERGONOMIA, II FÓRUM BRASILEIRO DE ERGONOMIA, 13 , CONGRESSO BRASILEIRO DE INICIAÇÃO CIENTÍFICA EM ERGONOMIA, 1, Fortaleza, 2004. Anais. .

BAIRD, G. et al. (Ed.). Building Evaluation Techniques. Wellington: Victoria University of Wellington; New York: McGraw-Hill, 1995.

BECHTEL, R. Environment \& Behavior - na introduction. Thousand Oaks (Califórnia): SAGE, 1997.

BINS ELY, V. Ergonomia + Arquitetura: buscando um melhor desempenho do ambiente
2. Por atividade compreendem-se os comportamentos: tomada de informações, gestos de acionamentos, posturas assumidas, comunicações, deslocamentos... (Moraes e Mont'Alvão, 2005).

3. Que nos Estados Unidos tem sido considerada uma atividade distinta da prática projetual.

4. Vinculado ao Programa de Pós-graduação em Arquitetura da FAU/UFRJ < www.fau.ufrj. br/prolugar $>$.

físico. In: CONGRESSO INTERNACIONAL DE ERGONOMIA E USABILIDADE DE INTERFACES HUMANO-TECNOLOGIA: PRODUTOS, PROGRAMAS, INFORMAÇÃO, AMBIENTE CONSTRUÍDO, 3, 2003. Anais... Rio de Janeiro: LEUI/PUC-Rio, 2003.

CASTRO, I. S. A importância da validação no processo de concepção de projetos. In: CONGRESSO BRASILEIRO DE ERGONOMIA, 13, FÓRUM BRASILEIRO DE ERGONOMIA, 2, CONGRESSO BRASILEIRO DE INICIAÇÃO CIENTÍFICA EM ERGONOMIA, 1, Fortaleza, 2004. Anais...

FISCHER, G. N. Psicologia Social do Ambiente. Lisboa: Instituto Piaget, 1994

FONSECA, J. F. A aplicação dos métodos de análise ergonômica na elaboração de projetos cromáticos para locais de trabalho. In: CONGRESSO BRASILEIRO DE ERGONOMIA, 13, FÓRUM BRASILEIRO DE ERGONOMIA, 2, CONGRESSO BRASILEIRO DE INICIAÇÃO CIENTÍFICA EM ERGONOMIA, 1, Fortaleza, 2004. Anais...

FONSECA, J. F. Cor nos locais de trabalho como aplicá-la de forma adequada às necessidades dos usuários e às exigências da tarefa? In: CONGRESSO BRASILEIRO DE ERGONOMIA, 14, Curitiba, 2006. Anais...

LATOUR, B. A Esperança de Pandora. Bauru, SP: EDUSC, 2001.

LYNCH, K. A Imagem da Cidade. Martins Fontes: São Paulo, 1960
5. Os atributos propostos por Abrantes (2004) foram elaborados a partir de quatro autores: Lynch (1960), Sommer (1979), Fischer (1994) e Tuan (1980).

6. A análise dos aspectos experienciais consiste em uma contribuição das pesquisas do PROLugar à metodologia da Intervenção Ergonomizadora.

MATURANA, H. Cognição, ciência e vida cotidiana. Belo Horizonte: Editora da UFMG, 2001.

MORAES, A. Abordagem sistêmica e sistemática: apreciação, diagnose, projetação, avaliação, validação. In: CONGRESSO INTERNACIONAL DE ERGONOMIA E USABILIDADE DE INTERFACES HUMANOTECNOLOGIA: PRODUTOS, PROGRAMA, INFORMAÇÃO, AMBIENTE CONSTRUÍDO, 3, 2003. Anais... Rio de Janeiro: LEUI/PUC - Rio, 2003.

MORAES, A.; MONT'ALVÃO, C. Ergonomia: conceitos e aplicações. Rio de Janeiro: A. de Moraes, 2005.

ORNSTEIN, S.; ROMÉRO, M. Avaliação Pós-Ocupação do Ambiente Construído. São Paulo: Nobel, 1992.

ORNSTEIN, S.; BRUNA, G.; ROMÉRO, M. Ambiente Construído \& Comportamento: Avaliação Pós-Ocupação e a Qualidade Ambiental. São Paulo: Studio Nobel, 1995.

ORNSTEIN, S. Desempenho do Ambiente Construído, Interdisciplinaridade e Arquitetura. São Paulo: FAUUSP, 1996.

PEDRO, R. Cognição e Tecnologia: Híbridos Sob o Signo do Artifício. Rio de Janeiro, 1996. Tese (Doutorado em Comunicação) - ECO-UFRJ.

PREISER, W. F. E. et al. Post-Occupancy Evaluation. New York: Van Nostrand Reinhold, 1988. 
PREISER, W. The International Building Performance Evaluation Project. In: Thorbjoern Mann (Ed.). The Power of Imagination. ANNUAL CONFERENCE OF THE ENVIRONMENTAL DESIGN RESEARCH ASSOCIATION, EDRA, 30, 1999. Proceedings... Orlando, Florida: EDRA, 2-6/jun 1999, p.13-19.

REIS, T. ERGO-ARQUITETURA: A Ergonomia como fator fundamental nos processos de projetação em arquitetura de locais de trabalho. In: CONGRESSO LATINO- AMERICANO DE ERGONOMIA, 6, CONGRESSO BRASILEIRO DE ERGONOMIA, 11, Gramado, 2001. Anais...

RHEINGANTZ, P. Centro Empresarial Internacional Rio: análise pós-ocupação, por observação participante, das condições internas de conforto. Rio de Janeiro, 1995. Dissertação (Mestrado em Arquitetura) - Faculdade de Arquitetura e Urbanismo, Universidade Federal do Rio de Janeiro.

Aplicação do Modelo de Análise Hierárquica COPPETEC-Cosenza na Avaliação do Desempenho de Edifícios de Escritório. Rio de Janeiro, 2000. Tese (Doutorado em Engenharia de Produção) - COPPE, UFRJ.

RHEINGANTZ, P.; DEL RIO, V.; DUARTE, C. S. Cultural Factors: A needed category for Post-Occupancy Evaluation. In: EDRA, 33. Proceedings... Pensylvania: EDRA, 2002. (abstract)

RHEINGANTZ, P. De Corpo Presente. In: NUTAU'2004. Anais... São Paulo: FAU/USP, 2004. RHEINGANTZ, P. et al. Observando a qualidade do lugar: Procedimentos para a Avaliação Pós-ocupação. Rio de Janeiro: Proarq/ FAU-UFRJ, 2008 (no prelo).

RODRIGUES, H. S. Cognição e experiência no ambiente de trabalho. Abordagem da Observação Incorporada na Avaliação Pós-ocupação: estudo de caso no centro de pesquisa da Fundação Casa de Rui Barbosa. Rio de Janeiro, 2005. Dissertação (Mestrado em Arquitetura) - PROARQ/FAU/UFRJ.

ROSCIANO, P. C. Reflexões sobre as interfaces entre a arquitetura e a análise ergonômica do trabalho - a concepção arquitetônica de espaços produtivos. In: CONGRESSO LATINOAMERICANO DE ERGONOMIA, 7, SEMINÁRIO BRASILEIRO DE ACESSIBILIDADE INTEGRAL, 1, CONGRESSO BRASILEIRO DE ERGONOMIA, 12, Recife, 2002. Anais...

SANOFF, H. Methods of Architectural Programming. Stroudsburg: Dowden, Hutchinson \& Ross Inc., 1977.

Participatory Design: Theory and Technique. Raleigh: Henry Sanoff, 1990.

Visual Research Methods in Design. Nova Iorque: Van Nostrand Reinhold, 1991.

SMITH, P.; KEARNY, L. Creating Workplaces Where People Can Think. San Francisco: JosseyBass Publishers, 1994.

SOMMER, R. A Conscientização do Design. São Paulo: Editora Brasiliense, 1979

THOMPSON, E. (1999). Human Consciousness: from Intersubjectivity to Interbeing. Disponível em: <http://www.philosophy.ucf.edu/pcsfetz1. $\mathrm{html}>$. Acesso em maio 2001

TUAN, Y. F. Topofilia. São Paulo: Difel, 1980.

VILLAROUCO, V. Modelo de avaliação de projetos - enfoque cognitivo e ergonômico. Florianópolis, 2001a. (Doutorado) - Programa de Pós-Graduação em Engenharia de Produção, UFSC.
Ambiente para o usuário, ou usuário para o ambiente? In: CONGRESSO LATINO- AMERICANO DE ERGONOMIA, 6 CONGRESSO BRASILEIRO DE ERGONOMIA 11, Gramado, 2001b. Anais..

Avaliação ergonômica do projeto arquitetônico. In: CONGRESSO LATINOAMERICANO DEERGONOMIA, 6, SEMINÁRIO BRASILEIRO DE ACESSIBILIDADE INTEGRAL, 1, CONGRESSO BRASILEIRO DE ERGONOMIA, 12, Recife, 2002. Anais...

O que é um ambiente ergonomicamente adequado? In: ENCONTRO NACIONAL DE TECNOLOGIA DO AMBIENTE CONSTRUÍDO ENTAC, 10, São Paulo, 2004. Anais..

VILLAROUCO, V. et al. Identificação de parâmetros para concepção de espaços ergonomicamente adequados à habitação social. In: CONGRESSO INTERNACIONAL DE ERGONOMIA E USABILIDADE DE INTERFACES HUMANO-TECNOLOGIA PRODUTOS, PROGRAMA, INFORMAÇÃO, AMBIENTE CONSTRUÍDO - Ergodesig, 5, 2005. Anais... Rio de Janeiro: LEUI/PUC, 2005.

Reflexões acerca da Ergonomia do Ambiente Construído. Recife: Ed. ABERGO 2007a. 9 Boletim da ABERGO - Associação Brasileira de Ergonomia.

O ambiente está adequado? In: ENCONTRO NACIONAL DE ERGONOMIA DO AMBIENTE CONSTRUÍDO, 1, SEMINÁRIO BRASILEIRO DE ACESSIBILIDADE INTEGRAL, 2, Recife, 2007b. Anais. .

ZEISEL, J. Inquiry by Design. Monterey: Brooks/ Cole Publishing Co., 1981.

\section{SOBRE OS AUTORES}

Juliane Figueiredo Fonseca.

Universidade Federal do Rio de Janeiro - UFRJ

Rio de Janeiro - RJ, Brasil

E-mail: julianearq@uol.com.br

\section{Paulo Afonso Rheingantz.}

Universidade Federal do Rio de Janeiro - UFRJ

Rio de Janeiro - RJ, Brasil

E-mail:par@ufrj.br 